\title{
Nutrition services by health providers during antenatal consultations in Senegal: a comparison of observed versus self- reported practices
}

\author{
Elhadji Alioune Badara Ningue ${ }^{1}$ (D) Isabelle Galibois ${ }^{1}$, Sonia Blaney ${ }^{2}$ \\ ${ }^{1}$ Faculté des sciences de l'agriculture et de l'alimentation, Laval University, Quebec, Canada, ${ }^{2}$ Faculté des sciences de la santé et des services \\ communautaires, Moncton University, Moncton, Canada \\ Keywords: antenatal care, pregnancy, nutrition services
}

https://doi.org/10.29392/001c.22234

\section{Journal of Global Health Reports}

Vol. 5, 2021

\section{Background}

Malnutrition is of concern among pregnant women in Senegal. This paper aimed to compare health providers' self-reported practices to their actual provision of nutrition services during antenatal care (ANC) consultations.

\section{Methods \\ A comparative study was conducted in a random sample of 27 health providers in the Kolda region. Two ANC consultations were monitored for each provider, and later compared to the data that were collected through a face-to-face interview. This provided us with the opportunity to assess the agreement between self-reported and observed actions namely clinical actions, verbal assessments and counseling.}

\section{Results \\ In general, the ANC providers reported similar extent of clinical actions that they performed. However, in verbal assessments, health providers over-reported inquiring about iron and folic acid intake (44\% observed vs $89 \%$ reported) and its potential side effects ( $0 \%$ vs $33 \%$ ), signs of vitamin A deficiency ( $0 \%$ vs $11 \%$ ) and intake of parasite prophylaxis (18\% vs $63 \%$ ). They also over-reported the provision of counseling on the importance of avoiding tea/coffee ( $41 \%$ observed vs $74 \%$ reported), gaining appropriate weight (14\% vs $44 \%$ ), and eating specific foods (7\% vs $52 \%$ ).}

\section{Conclusions}

Nutrition services during ANC should be improved, especially in the domains of verbal assessment and nutrition counseling. The possible causes of these discrepancies might be the time constraint for ANC, limited skills, or a low demand of pregnant women for nutritional guidance. Nutrition training and/or supportive supervision of health providers deserve more attention in order to improve the nutrition services and the overall quality of ANC.

In low and middle-income countries, under- and over nutrition, as well as micronutrient deficiencies, still affect a significant proportion of women. ${ }^{1}$ This situation may have deleterious impacts on woman and child health, and perpetuates the intergenerational cycle of malnutrition and of poor development. ${ }^{2}$ Malnutrition during pregnancy has been associated with increased maternal mortality, haemorrhage and neonatal death as well as with an increased risk of developing gestational diabetes and pre-eclampsia. ${ }^{2}$ More attention is therefore warranted on maternal nutrition. Recently, Da Silva et al. ${ }^{3}$ highlighted the limited progress in addressing maternal nutrition problems over the past few decades, despite the availability of evidencebased interventions. ${ }^{4,5}$ One key platform to address maternal nutrition is through antenatal care (ANC) services.
In Senegal, efforts have been taken to accelerate progress toward the reduction of anemia during pregnancy, as it affects two thirds of pregnant women in this country. 6,7 Guidelines have also been issued to detail components of each of the four recommended ANC visits. ${ }^{7}$ Yet, the coverage of nutrition services during ANC is not optimal, since about $40 \%$ of Senegalese pregnant women do not attend the minimum of four antenatal care visits and a similar proportion does not benefit from the recommended amount of iron and folic acid (IFA) supplements. ${ }^{8}$

The situation is even worse in less affluent regions of Senegal. We have recently documented the availability of material resources, the qualifications of ANC providers and their self-assessment of the provision of nutrition services to pregnant women during ANC visits in health facilities lo- 
cated in the Kolda region, Eastern Senegal. ${ }^{9}$ Overall, results showed that a majority of health facilities had the material resources to provide nutrition services. Health providers also had the required qualifications (being a midwife or a nurse) to conduct ANC, but only $20 \%$ were trained on maternal nutrition. Concerning the offer of nutrition services, while the self-assessment method has the merit of providing information on practices and appreciation that providers may have on their work, it has limitations. For instance, responses or knowledge information gained through a self-report assessment may not be translated into practice. ${ }^{10-12}$ Self-reporting may also induce a social desirability bias defined as the "tendency of one to underreport socially undesirable attitudes and behaviors and to over report more desirable attributes." 13 Alternatively, structured direct observations have been proposed to gather information on actual practices with regards to quality of care. ${ }^{10,14,15}$

The aim of this study was to assess nutrition-related services provided by health providers during ANC using repeated direct observations and to compare results with the self-assessment of health providers.

\section{METHODS}

\section{CONCEPTUAL FRAMEWORK, AND PREPARATORY WORK}

The Donabedian conceptual framework ${ }^{16}$ developed to examine health services and their quality guided the current research. It refers to three components namely the structure, the process and the outcome. Given the objective of this paper, the focus is on the process component, specifically on the technical process or how care is delivered. ${ }^{16}$

Before undertaking the data collection, local surveyors were recruited and trained on survey tools and methodology 9 which were adapted from the "Quality Assessment of Nutrition Services" package developed by Helen Keller International (HKI). ${ }^{17}$ Specifically, the survey tools from the HKI package used in this study were the ANC observation grid and a questionnaire for the interview with the providers. ${ }^{17}$ Both tools consisted of the same exhaustive list of services that could be provided during ANCs including clinical actions, verbal assessments and specific counseling services. Most of these services were related to nutrition, while others on different antenatal care topics. Survey tools were all pre-tested with providers offering ANCs in a rural area located in Dakar neighbourhood health facilities upon completion of the in-class training.

\section{STUDY SITE AND SAMPLING}

This comparative study was conducted in the Kolda region in Eastern Senegal. This area has a population of about 750000 inhabitants. ${ }^{18}$ Recent data indicate that only $36 \%$ and $24 \%$ of pregnant women of the region are receiving respectively at least 90 iron and folic acid tablets and dewormers during their pregnancy. ${ }^{8}$ No information is available on the number of ANC visits attended by pregnant women for this region.

The complete list of 88 providers offering ANC in all 65 health facilities of the region was compiled and from this list, 30\% (or 27) providers were randomly selected to participate in the study. In addition, two pregnant women present in the health facilities at the moment of the survey were recruited by convenience sampling as they were waiting to attend their consultation with each of the selected health provider. Before undertaking the data collection, written consents were obtained from all health providers and pregnant women. In the case where a pregnant woman was not able to sign, a designated witness signed in the woman's place and the woman's verbal consent was electronically recorded. Ethics approvals were obtained from relevant authorities.

\section{DATA COLLECTION}

The data collection was carried out in December 2018 and January 2019 by five teams of two surveyors.

For each selected health provider, a medically trained female surveyor (i.e., a midwife or nurse) was present in the consultation room during two different ANC consultations, one for each participating pregnant woman. In a non-intrusive manner and using the observation grid, this enumerator recorded whether or not (yes or no) every clinical action, verbal assessment and counseling service listed on the grid was performed by the health provider during the ANC. The duration of the consultation was also recorded. One nonobserved consultation was intercalated between the two observed consultations with participant pregnant women.

Upon completion of both observed consultations, selfreported data on the same ANC services were collected through a face-to-face interview with the health provider in a private location of his/her facility using the questionnaire described above. The interview was performed by one of the enumerators available at the end of the day regardless of his/her gender. For each clinical action/assessment/service, the health provider was asked to indicate the frequency that he/she was regularly offering it. To do so, four choices of responses were offered namely: always, most often, not often, never.

To further avoid biases due to the observer's presence during direct observations, and with the approval of the two ethics committees, the specific purpose of this study was not disclosed to providers and pregnant women. The study`s objective revealed to participants was more general and it was presented as to be a measurement of the overall services offered during ANC. However, at the end of the data collection period in each health facility, the specific objective of the research was shared with all participants including pregnant women to allow them to revoke their consent if they wished; in such case, their data would be destroyed. However, none of the participants chose to revoke their consent.

At the end of each day of data collection, all survey tools were reviewed by the main author to ensure completeness and accuracy.

\section{DATA ANALYSIS}

The data entry was performed by the main author, his assistant and two of the enumerators with experience in data entry and cleaning.

For each observed action/assessment/service, every health provider was assigned a score or 1 (yes) if the practice 
was observed twice (meaning during the two ANC consultations, with each pregnant woman). A score 0 (no) was assigned if the practice was not observed at all during the two ANC consultations or if observed just once. Number and proportion (\%) of health providers with a score of 1 were calculated for each practice.

Data collected on self-reported practices were analyzed as follows: for each practice, the number and proportion (\%) of health providers who reported as executing either an action, an assessment or offering the service "always" during ANC consultations were calculated.

Data were analyzed with $\mathrm{R}$ Studio software (version 1.3.1093). Proportions or numbers of observed actions/assessments/services were compared to self-reported responses. Chi-square independence test was performed to compare proportions between observed and self-reported practices for items with 5 observations and above in each cell of the 2 by 2 contingency table while the Fischer's Exact test was used when the number of observations in one cell was below 5 . A $P$-value below 0.05 was considered to indicate significant difference between proportions.

\section{RESULTS}

In total, we observed 54 ANC consultations, with two consultations by each of the 27 health providers. The observed consultations had an average duration of $29 \pm 15$ minutes, with a minimum recorded length of 12 minutes and a maximum recorded length of 76 minutes.

Clinical actions, both observed and self-reported, are presented in Table 1. The most often (>90\%) observed and self-declared clinical actions were doing breast exam, taking weight measurement and checking blood pressure. Taking a blood sample was the least self-reported, with 7 out of 10 health providers claiming to always perform this clinical action. The least observed $(<65 \%)$ clinical actions were checking the vaccination card and listening to foetal heartbeat. With the exception of listening to foetal heartbeat $(P=0.028)$, proportions of health providers who reported implementing each action were not significantly different from those for whom observations were made.

Results of direct observations of verbal assessments conducted during ANC, also reported in Table 1, show that between 60 to $70 \%$ of health providers were asking pregnant women if they were sleeping under bed net as well as asking about their last tetanus toxoid injection and human immunodeficiency virus (HIV) status. Proportions of health providers observed doing other types of assessments were below $50 \%$. Around $45 \%$ enquired to pregnant women about IFA intake and appetite while around $30 \%$ of them were observed asking women about their eating, sleeping and resting habits. A lower proportion (below $20 \%$ ) of health providers were observed asking about the intake of a parasite prophylaxis and the use of iodized salt at household level. For some of the verbal assessments such as woman`s plan for breastfeeding, side effects of IFA supplementation and signs of vitamin A deficiency, the practice was not observed at all for any health provider.

Proportions of health providers who self-reported doing verbal assessments during ANC were significantly higher than those among whom practices were observed with re- gards to asking about IFA intake $(P=0.002)$ and potential side effects $(P=0.003)$, malaria prevention medicine $(P=0.001)$ and parasite prophylaxis $(P=0.001)$ intakes and plan about exclusive breastfeeding $(P=0.001)$.

Counseling services observed during ANC consultations and self-reported by health providers are shown in Table $\underline{2}$. With regards to observed practices, results show that almost all health providers talked about side effects of IFA supplementation. Around $80 \%$ highlighted the importance of taking these supplements while 6 out of 10 talked about the importance of taking means for malaria prevention (either malaria prophylaxis or sleeping under bed net) and suggested to pregnant women to be tested for HIV. Half of health providers were observed as providing general dietary advice and suggesting eating specific foods as well as providing counseling on danger signs during pregnancy while around $40 \%$ of them were suggesting the avoidance of coffee and tea, reducing workload and increasing sleeping/ resting hours. About $30 \%$ of them gave advice on exclusive breastfeeding.

As it was the case for verbal assessments, proportions of health providers who self-reported providing each counseling service were generally higher than those among whom the practice was actually observed especially for the followings: suggests being tested for HIV $(P=0.019)$, advises about danger signs during pregnancy $(P=0.018)$, provides advice on exclusive breastfeeding $(P=0.003)$, talks about the importance of gaining adequate weight $(P=0.035)$ and suggests specific food for that purpose $(P=0.007)$, as well as explains the role of amenorrhea as a method for birth spacing $(P=0.007)$. Yet, the opposite was noted for the proportion of health providers who were observed talking about potential effects of IFA supplements, which was three times higher than the proportion who self-reported doing it $(P<0.001)$.

\section{DISCUSSION}

The results of this study show a high level of concordance between self-reported and observed practices for clinical actions, while more discrepancies were found between both sets of data with regards to verbal assessments and counseling services. In fact, for verbal assessments, health providers were over-reporting six out of 15 actions, among whom five were related to nutrition. Interestingly, some nutrition verbal assessment patterns were observed and self reported in comparable proportions by health providers, such as asking women about their appetite and eating habits. The gaps between observed and self-reported data were noted for nine out of 19 services, five of them being directly related to nutrition. In particular, large differences were noted between observed and self-reported data for counseling on the importance of gaining weight and advising on specific foods to eat to do so. On a more positive note, a larger proportion of health providers were observed talking about potential side effects of IFA as compared to those who self-reported it. Although limited to about a half of providers, similar proportions self-reported and were observed as providing general dietary advice and talking about eating specific foods to pregnant women.

Differences between self-reported and observations data have been documented in individuals or families for food 
Table 1. Description of clinical actions and verbal assessments during antenatal care visits

\begin{tabular}{|c|c|c|c|}
\hline & $\begin{array}{l}\text { Percentages of observed } \\
\text { practices }\end{array}$ & $\begin{array}{l}\text { Percentages of self-reported } \\
\text { practices* }\end{array}$ & $P$-values \\
\hline \multicolumn{4}{|l|}{ Clinical actions } \\
\hline Performs a breast exam & 96 & 96 & 1 \\
\hline Measures weight & 93 & 100 & 0.491 \\
\hline Checks blood pressure & 93 & 96 & 1 \\
\hline Measures height & 89 & 89 & 1 \\
\hline $\begin{array}{l}\text { Checks for signs of anaemia (e.g. pale hand } \\
\text { palm/inner eyelids) }\end{array}$ & 85 & 89 & 1 \\
\hline Takes a blood sample & 81 & 70 & 0.524 \\
\hline Measures uterine height & 74 & 93 & 0.141 \\
\hline Takes an urine sample & 74 & 82 & 0.743 \\
\hline Measures mid-upper arm circumference & 70 & 89 & 0.175 \\
\hline Measures woman's temperature & 70 & 78 & 0.756 \\
\hline Checks for oedema & 70 & 85 & 0.326 \\
\hline Listens to fetal heartbeat & 59 & 89 & 0.028 \\
\hline \multicolumn{4}{|l|}{ Verbal assessment items } \\
\hline Asks about knowledge of HIV status & 70 & 85 & 0.326 \\
\hline $\begin{array}{l}\text { Asks if sleeping under a long-lasting } \\
\text { impregnated bed net }\end{array}$ & 63 & 89 & 0.054 \\
\hline Asks about last tetanus toxoid injection & 63 & 82 & 0.224 \\
\hline Asks about daily workload & 52 & 44 & 0.586 \\
\hline Asks about appetite & 48 & 52 & 0.785 \\
\hline Asks about iron/folate intake & 44 & 89 & 0.002 \\
\hline $\begin{array}{l}\text { Asks about medicine (Fansidar) intake for } \\
\text { malaria prevention }\end{array}$ & 33 & 78 & 0.001 \\
\hline Asks about eating habits & 26 & 30 & 1 \\
\hline Asks about sleeping and resting habits & 26 & 26 & 1 \\
\hline $\begin{array}{l}\text { Asks about intake of parasite prophylaxis or } \\
\text { treatment }\end{array}$ & 18 & 63 & 0.001 \\
\hline $\begin{array}{l}\text { Asks about the use of iodized salt in woman's } \\
\text { household }\end{array}$ & 15 & 33 & 0.202 \\
\hline Asks about plan to exclusively breastfeed & 0 & 41 & 0.007 \\
\hline $\begin{array}{l}\text { Ask about potential side effects of iron/folate } \\
\text { supplements }\end{array}$ & 0 & 33 & 0.003 \\
\hline
\end{tabular}

* Proportions of health providers claiming to always perform the practice during ANC consultation

Note: Proportion of observed practices ( $\mathrm{N}=54$ observations) and of self-reported practices by ANC providers ( $\mathrm{N}=27$ providers).

hygiene ${ }^{19-21}$ as well as for health-related behaviors. ${ }^{13}$ In the present study as in others, the divergence between both sets of data might be due in part to the social desirability bias $^{13,19}$ Yet, precautions were taken to limit this bias. Firstly, information on the real purpose of the study (which was investigating primarily nutrition services) was not divulgated to health providers before the data collection. This may have limited the over-reporting on these specific practices. ${ }^{14,19,22}$ Secondly, two observation sessions of ANC were held with each health provider to minimize the social desirability bias. ${ }^{21}$ Lastly, interviews to collect self-reported data were conducted after the observations, again to limit over self-reporting. ${ }^{20}$ On the other hand, although there might have been a social desirability bias in this research, it probably applies to all observations as health providers may not have been tempted to report or implement nutrition-related practices more than other practices performed during ANC.

Similar to our context, other research using direct observations showed that clinical actions are generally performed by larger proportions of health providers as compared to verbal assessment and counseling services. For instance, in Lao People's Democratic Republic, a higher proportion of health care providers were observed taking information on the medical history of pregnant women such as asking age, taking blood pressure, examining oedema, and 
Table 2. Description of counseling services provided during antenatal care visit

\begin{tabular}{|c|c|c|c|}
\hline Action points included in counseling & $\begin{array}{l}\text { Percentages of } \\
\text { observed practices }\end{array}$ & $\begin{array}{l}\text { Percentages of self- } \\
\text { reported practices }\end{array}$ & $P$-values \\
\hline $\begin{array}{l}\text { Talks about potential side effects of iron and folic acid } \\
\text { supplements }\end{array}$ & 99 & 33 & 0.001 \\
\hline $\begin{array}{l}\text { Talks about the importance of taking iron/folate } \\
\text { supplements regularly }\end{array}$ & 78 & 85 & 0.728 \\
\hline Suggests testing for HIV/AIDS & 63 & 93 & 0.019 \\
\hline $\begin{array}{l}\text { Talks about the importance of taking malaria } \\
\text { prophylaxis }\end{array}$ & 63 & 85 & 0.119 \\
\hline $\begin{array}{l}\text { Talks about the importance of sleeping under a long- } \\
\text { lasting impregnated bed net }\end{array}$ & 63 & 85 & 0.119 \\
\hline Provides advice on danger signs (fever, pain) & 52 & 85 & 0.018 \\
\hline Suggests specific foods & 52 & 48 & 0.785 \\
\hline $\begin{array}{l}\text { Talks about the importance of taking parasite } \\
\text { prophylaxis or treatment }\end{array}$ & 48 & 63 & 0.273 \\
\hline Provides general dietary advice & 48 & 59 & 0.413 \\
\hline Suggests to reduce workload & 44 & 56 & 0.414 \\
\hline Suggests the avoidance of coffee and tea & 41 & 74 & 0.013 \\
\hline Suggests to increase sleeping/resting hours & 41 & 44 & 0.783 \\
\hline Provides advice on exclusive breastfeeding & 27 & 67 & 0.003 \\
\hline Suggests the avoidance of alcohol products & 26 & 44 & 0.154 \\
\hline Suggests the avoidance of tobacco products & 26 & 44 & 0.154 \\
\hline Talks about the importance of using iodized salt & 18 & 33 & 0.352 \\
\hline Talks about the importance of gaining adequate weight & 14 & 44 & 0.035 \\
\hline $\begin{array}{l}\text { Provides advice on specific foods to eat to gain } \\
\text { adequate weight }\end{array}$ & 7 & 52 & 0.007 \\
\hline $\begin{array}{l}\text { Explains the lactational amenorrhea method for birth } \\
\text { spacing }\end{array}$ & 0 & 41 & 0.007 \\
\hline
\end{tabular}

Note: Proportion of observed practices $(\mathrm{N}=54)$ and of self-reported practices by ANC providers $(\mathrm{N}=27)$.

listening heartbeat of the foetus as compared to health promotion interventions such as advising women to eat a variety of foods and not restricting any, as well as giving IFA. ${ }^{14}$

In light of the aforementioned results, even though we previously reported that required inputs and equipment are available in health facilities in Kolda area and that health providers seem to have the required qualifications, ${ }^{9}$ this does not necessarily lead to the delivery of quality care, as also notified elsewhere. ${ }^{10,15,23}$ The present study indicates that delivery of quality nutrition services may be particularly worrisome. For instance, as opposed to enquiring about HIV status, the use of bed net and immunization status and asking about daily workload, verbal assessment related to the provision of nutrition services were observed in less than $50 \%$ of health providers. Some verbal assessments pertaining to nutrition were not even observed at all, such as asking about side effects of IFA and signs of vitamin A deficiency, which is worrying. For counseling services, with the exception of almost all health providers talking about potential side effects of IFA (but not necessarily asking if women had any of these effects), in general, less than $50 \%$ of them were observed as providing nutrition counseling services. Only $7 \%$ and $14 \%$ were respectively providing counseling on the importance of gaining weight and advice on eating specific foods to do so.

These results suggest that nutrition-related assessment and counseling services do not seem to be a priority during ANC in Kolda area. Unfortunately, findings from both observation and self-assessment appear to support this assumption. So, why is that so? Several reasons may explain the lower priority given to nutrition services during ANC. For instance, as observed in Tanzania, ${ }^{10}$ it seems that health workers do prioritize some services over others. Could it be that health providers feel more comfortable in doing specific actions (such as clinical actions) over others because of previous trainings that may have led to improved/better skills and knowledge on these topics, as it was pointed out for hand-washing practices among child caregivers in Malawi? ${ }^{19}$ Or might it be because health providers may not be aware about guidelines on nutrition services during $\mathrm{ANC}^{24}$ or because they do not have sufficient time to perform all expected actions/assessments? With regards to the later assumption, the average time spent on an ANC in this study was 29 minutes, slightly less than the WHO recommended duration of 30 to 40 minutes for the first ANC consultation, ${ }^{25}$ and much shorter than the average duration 
of above 45 minutes for an ANC consultation reported by other studies conducted in developing countries. ${ }^{26,27}$ Or, as pointed out by Solnes Miltenburg et al., ${ }^{10}$ are there some services for which health providers believe that they will be held more accountable than others? Lastly, is the prioritization amongst all actions/assessments influenced by women's expectations ${ }^{10}$ or in other words, do women look forward to get nutrition services or do they rather expect tangible services such as receiving some medications and immunization? These areas certainly deserve to be investigated.

\section{LIMITATIONS AND STRENGTHS}

Social desirability bias is the main limitation of this study; although direct observation allows a better overview of the reality in comparison to self-reporting information, it leads to inevitable changes in the behavioural pattern. Although precautions were taken in the current study to minimize this bias, it could be reduced even more in future research. For instance, the covert observation method in which subjects are observed without being aware of it could be used to obtain a more reliable measurement of actions/assessments that are implemented during ANC. ${ }^{14}$ Conducting multiple observations can also help at mitigating this impact. ${ }^{15} \mathrm{Fi}$ nally, although the sample size may be considered as small, we believe that the context observed among the selected health providers is representative of those of other rural facilities in Kolda region.

To the best of our knowledge, this is the first study investigating nutrition services actually provided during ANC in an African country. Secondly, two different methods were used to get an overview of nutrition services during ANC and thirdly, nutrition services were assessed in a comprehensive way, suggesting that findings of this study may be considered valid.

\section{CONCLUSIONS}

Overall, observation data and, to a lesser extent, self-reported information show that nutrition-related assessments and counseling services are not given full attention during ANC in Kolda area. Taking action to improve the offer of quality nutrition services during ANC is warranted. To do so, trainings and supportive supervision could be beneficial for developing and strengthening knowledge and skills but also it could contribute to motivate health providers to implement nutrition services. ${ }^{28}$ Moreover, during supportive supervision, instead of assessing the provision of services through self-reported or administrative data, using direct or covert observations as well as simulations should be encouraged in order to provide a full perspective of the actions/assessments that are really performed during ANC.

\section{ACKNOWLEDGEMENTS}

We are grateful to all participants and enumerators for their contributions to the study.

We would like to thank Pr Mohamadou Sall, Director of the IPDSR at the University Cheikh Anta Diop for his outstanding support and contribution to the implementation of this research.

\section{ETHICS APPROVAL AND CONSENT TO PARTICIPATE}

This research was approved by the Human Research Ethics Committee of Laval University (\# 2018-139 A-1/ 19-12-2018) and by the Comité National d'Éthique pour Ia Recherche en Santé (CNÉRS) of the Ministry of Health and Social Action of Senegal (\#000103).

\section{AVAILABILITY OF DATA AND MATERIALS}

The datasets used and/or analysed during the current study are available from the corresponding author on reasonable request.

\section{DECLARATIONS}

The informed consent obtained from study participants was written, using consent forms that are signed by the enumerator and the research participant.

In the case where the participant could not sign, a designated witness signed in the participant's place and the participant's verbal consent was recorded on an electronic medium (dictaphone or cell phone) as requested by the $\mathrm{Hu}$ man Research Ethics Committee of Laval University.

\section{FUNDING}

The authors disclosed receipt of the following financial support for the research, authorship, and/or publication of this article: the financial support from the Queen Elizabeth scholarship programme funded by the International Development Research Center /IDRC and the Social Sciences and Humanities Research Council of Canada /SHRC is acknowledged.

\section{AUTHORSHIP CONTRIBUTIONS}

EABN: Conceptualization, Methodology, Formal analysis, Investigation, Data Curation, Writing - Review \& Editing, Visualization

IG: Conceptualization, Methodology, Formal analysis, Data Curation, Writing - Review \& Editing, Visualization, Project administration.

SB: Conceptualization, Methodology, Formal analysis, Data Curation, Writing - Review \& Editing, Visualization, Project administration, Funding acquisition.

All authors have read and approved the submitted version of the manuscript.

\section{COMPETING INTERESTS}

The authors completed the Unified Competing Interest format www.icmje.org/coi disclosure.pdf (available upon request from the corresponding author), and declare no conflicts of interest. 


\section{CORRESPONDENCE TO:}

Elhadji Alioune Badara Ningue

Ph.D. Nutrition Candidate

École de nutrition

Faculté des sciences de l'agriculture et de l'alimentation, Laval University
2425, rue de l'Agriculture, Québec, QC, Canada, G1V 0A6 Elhadji-al-badara.ningue.1@ulaval.ca

Submitted: February 03, 2021 GMT, Accepted: March 21, 2021 GMT 


\section{REFERENCES}

1. Development Initiatives. Global Nutrition Report 2020: Action on Equity to End Malnutrition.

2. Black RE, Victora CG, Walker SP, et al. Maternal and Child Undernutrition and Overweight in Low-Income and Middle-Income Countries. The Lancet. 2013;382(9890):427-451. doi:10.1016/s0140-6736(1 3)60937-x

3. de Silva A, Untoro J, Blankenship J, Udomkesmalee E. Regional Overview on Maternal Nutrition and Examples of Health System Programme and Policy Responses: Asia and the Pacific. Ann Nutr Metab. 2019;75(2):131-134. doi:10.1159/000503672

4. WHO Reproductive Health Library. WHO recommendation on multiple micronutrient supplementation during pregnancy. World Health Organization. Published 2016. Accessed May 6, 2020. https://extranet.who.int/rhl/topics/preconception-pre gnancy-childbirth-and-postpartum-care/antenatal-ca re/who-recommendation-multiple-micronutrient-sup plementation-during-pregnancy

5. World Health Organization. Essential nutrition actions: Mainstreaming nutrition through the lifecourse. World Health Organization; 2019.

6. Cellule de lutte contre la malnutrition. Accessed August 3, 2020. http://intomorrowetrust.com/a-propo s/presentation/

7. Ministère de la Santé et de l'Action Sociale (MSAS). Politiques, Normes et Protocoles (PNP) en Santé de la Reproduction. MSAS; 2018.

8. Agence Nationale de la Statistique et de la Démographie (ANSD) [Sénégal], ICF. Sénégal: Enquête Démographique et de Santé Continue (EDS-Continue 2017). ANSD \& ICF; 2018.

9. Ningue EAB, Galibois I, Blaney S. Antenatal nutrition services offer in primary health care facilities of Kolda region, Senegal. J Glob Health Rep. 2020;4:e2020103. doi:10.29392/001c.18087

10. Solnes Miltenburg A, van der Eem L, Nyanza EC, et al. Antenatal care and opportunities for quality improvement of service provision in resource limited settings: A mixed methods study. Puebla I, ed. PLoS ONE. 2017;12(12):e0188279. doi:10.1371/journal.pon e.0188279

11. Pedersen DM, Keithly S, Brady K. Effects of an Observer on Conformity to Handwashing Norm. Percept Mot Skills. 1986;62(1):169-170. doi:10.2466/p ms.1986.62.1.169
12. Ampt A, Westbrook J, Creswick N, Mallock N. A comparison of self-reported and observational work sampling techniques for measuring time in nursing tasks. J Health Serv Res Policy. 2007;12(1):18-24. doi:1 $\underline{0.1258 / 135581907779497576}$

13. Latkin CA, Edwards C, Davey-Rothwell MA, Tobin KE. The relationship between social desirability bias and self-reports of health, substance use, and social network factors among urban substance users in Baltimore, Maryland. Addict Behav. 2017;73:133-136. doi:10.1016/j.addbeh.2017.05.005

14. Phommachanh S, Essink DR, Wright EP, Broerse JEW, Mayxay M. Do health care providers give sufficient information and good counseling during ante-natal care in Lao PDR?: An observational study. BMC Health Serv Res. 2019;19(1):449. doi:10.1186/s12 913-019-4258-z

15. Leslie HH, Malata A, Ndiaye Y, Kruk ME. Effective coverage of primary care services in eight highmortality countries. BMJ Glob Health.

2017;2(3):e000424. doi:10.1136/bmigh-2017-000424

16. Donabedian A. The quality of care. How can it be assessed? JAMA. 1988;260(12):1743-1748. doi:10.100 1/jama.260.12.1743

17. Helen Keller International: Quality assessment of nutrition services. A how to guide. Surveying nutrition-related services offered to pregnant women, postpartum women, and caregivers of children under five in health facilities. Helen Keller Worldwide. Published online 2004.

18. Agence nationale de la statistique et de la démographie. Ministère de l'économie, des finances et du plan: La population du Sénégal en 2017. Dakar; 2017:2018.

19. Chidziwisano K, Tilley E, Morse T. Self-Reported Versus Observed Measures: Validation of Child Caregiver Food Hygiene Practices in Rural Malawi. Int J Environ Res Public Health. 2020;17(12):4498. doi:10.3 390/ijerph17124498

20. Dharod JM, Pérez-Escamilla R, Paciello S, Bermúdez-Millán A, Venkitanarayanan K, Damio G. Comparison between Self-Reported and Observed Food Handling Behaviors among Latinas. J Food Prot. 2007;70(8):1927-1932. doi:10.4315/0362-028x-70.8.1 $\underline{927}$ 
21. Curtis V, Cousens S, Mertens T, Traore E, Kanki B, Diallo I. Structured observations of hygiene behaviours in Burkina Faso: Validity, variability, and utility. Bull World Health Organ. 1993;71(1):23-32.

22. Stanton BF, Clemens JD, Aziz KM, Rahman M. Twenty-four-hour recall, knowledge-attitude-practice questionnaires, and direct observations of sanitary practices: A comparative study. Bull World Health Organ. $1987 ; 65(2): 217-222$.

23. Lagarde M, Sall M, Kovacs RJ 2. Enquête sur la qualité des soins de santé primaires au Sénégal. London School of Hygiene and Ttropical Medecine; 2018.

24. Nankumbi J, Ngabirano TD, Nalwadda G. Maternal Nutrition Education Provided by Midwives: A Qualitative Study in an Antenatal Clinic, Uganda. Huerta JM, ed. J Nutr and Metab. 2018;2018(3987396):1-7. doi:10.1155/2018/3987396

25. World Health Organization. WHO antenatal care randomized trial: Manual for the implementation of the new model.; 2002. Accessed December 23, 2020. http s://apps.who.int/iris/handle/10665/42513
26. von Both C, Flessa S, Makuwani A, Mpembeni R, Jahn A. How much time do health services spend on antenatal care? Implications for the introduction of the focused antenatal care model in Tanzania. BMC Pregnancy Childbirth. 2006;6(1):22. doi:10.1186/147 1-2393-6-22

27. World Health Organization. Impact of HRP research in maternal and perinatal care: A case-study. UNDP/UNFPA/WHO/World Bank Special Programme of Research, Development and Research Training in Human Reproduction (HRP). External evaluation 2003-2007; 2008.

28. Yeasmin L, Akter S, Shahidul Islam AM, Mizanur Rahman M, Akashi H, Jesmin S. Targeted interventions of ultra-poor women in rural Rangpur, Bangladesh: Do they make a difference to appropriate cooking practices, food habits and sanitation? J Biosoc Sci. 2014;46(4):419-430. doi:10.1017/s0021932013000 667 